\title{
Effects of Combination of Platelet Rich Plasma and OSTEON Material in Rabbits Bone Healing (A comparative study)
}

Fidaa S Abdo BDS

Mohammed kh Hasouni BDS, FDSRCPS (Lect.)
Department of Oral \& Maxillofacial Surgery

College of Dentistry, University of Mosul

Department of Oral \& Maxillofacial Surgery

College of Dentistry, University of Mosul



\begin{abstract}
Aims: The purpose of this study is to evaluate the effects of OSTEON, PRP and the combination of both of them on the healing of experimentally induced bone defects in rabbits. Materials and Methods: Fifteen domestic rabbits were used in this study; four bone defects were made in the tibia of each rabbit. The defects were filled with OSTEON, PRP, OSTEON / PRP and the other left unfilled as control. Specimens were collected at one, two and four weeks after surgery. Radiographical and histological examinations were used to evaluate healing depending of the amount of new bone formed. Results: It was found that the OSTEON / PRP combination led to a significant healing compared to other groups at first week only. On the other hand PRP alone showed better result than OSTEON alone in the three periods. Conclusion: It was concluded that PRP plasma exert a beneficial effect on healing process when added to bone substitute material OSTEON.
\end{abstract}

Keywords: bone defect, platelet rich plasma, OSTEON material

Abdo FS. Hasouni MK. Effects of Combination of Platelet Rich Plasma and OSTEON Material in Rabbits Bone Healing (A comparative study) Al-Rafidain Dent J. 2014; 14(1):90-100.

Received:17/10/2012 Sent to Referees:22/10/2012

Accepted for Publication: 5/12/2012

\section{INTRODUCTION}

Atrophy of alveolar bone after tooth loss is a common clinical problem and may affect esthetic, functional and structural aspects of treatment. ${ }^{(1)}$ Cancers of the head and neck often involve the mandible or the maxilla. This may require sectioning of bone with the tumor which leaves the patients permanently disfigured (2) Bone loss also can be a result of high energy trauma or birth defects. ${ }^{(31)}$

Various types of bone grafts have been developed for maxillofacial surgery such as autogenic bone grafts, allogenic bone and xenogenicBone graft. ${ }^{(3)}$

Autograft is considered as the gold standard in craniofacial surgery. ${ }^{(4)}$ Search for a synthetic biomaterial that is able to successfully replace normal tissue has taken a great interest to find a material that mimic one or more properties of natural bone. ${ }^{(5)}$ OSTEON is one of the alloplastic materials composed of hydroxyapatite (HA) $70 \%$ and beta-tricalcium phosphate (ß- TCP) 30\% which are most close to major mineral components of human bone. OSTEON is osteoconductive material acts as a bone growth scaffold. It has interconnected porosity structure which is similar to that of human cancellous bone. ${ }^{(6)}$

PRP is an autologous product that is derived from whole blood through the process of gradient density centrifugation. ${ }^{(7)}$ Platelets isolated growth factors 
include platelet derived growth factor (PDGF), transforming growth factors-beta (TGF-beta), vascular endothelial growth factor (VEGF), and epithelial growth factor (EGF). Being autologous, PRP is safe with no risk of disease transmission or immunogenic reactions and provides antibacterial protection. It is cost effective and can readily available at the dental clinic. ${ }^{(8)}$ PRP has been used in a variety of surgical procedures in the field of oral and maxillofacial surgery such as bone grafts, implants and maxillofacial reconstructions. ${ }^{(9)}$

\section{MATERIALS AND METHODS}

\section{OSTEON}

The material used in this study, OSTEON, is bone graft material manufactured by Dentium Company, Korea. It is first released to the market on October 2005 and obtained the CE approval on May 2006. It has white color particle and it is contained within vials. It is composed of hydroxyapatite (HA) $70 \%$ and betatricalcium phosphate (ß- TCP) 30\% which are most close to major mineral components of human bone.

\section{Preparation of platelets rich plasma}

A blood sample of 2 milliliters was taken from the heart of each rabbit prior to surgical procedure. Cardiac puncture in the anesthetized rabbit is done with a gauge 23 needle. The needle is inserted through the lateral chest wall at the cardiac impulse or inserted just caudal to the xiphoid cartilage. The needle is hold at 30 - angle above the plane of the abdomen and directing it in caudocephalic direction. Once the needle is within the heart, blood will collect into the syringe ${ }^{(10)}$.

The collected blood is combined with $0.5 \mathrm{ml}$ of citrate dextrose phosphate anticoagulant (ACD- A) in sterile test tube to prevent coagulation before centrifuging. The blood was centrifuged first at 2000 rpm for $10 \mathrm{~min}$. The plasma was drawn from the top and centrifuged for an additional $10 \mathrm{~min}$. at $3200 \mathrm{rpm}$. The plasma containing the platelets was drawn from the bottom for a third cycle of centrifuge at for $5 \mathrm{~min}$. at $4000 \mathrm{rpm}$ to increase the concentration of platelets. The PRP then was combined with equal volume of sterile solution of $\mathrm{CaCl} 2$ at the time of application which activates the platelets to release the growth factors. After activation, PRP turned into gel- like solution

\section{Experimental Model}

Fifteen healthy male and female adult domestic rabbits weighting $1.32 .5 \mathrm{Kg}$ were used in this study. The animals were kept under standard conditions of feeding and housing and were given standard diet of leafy vegetables and water. This study was done in the College of Dentistry University of Mosul. The habitant of the animal during the experiment was the animal house of the same mentioned college. Animals' examination was performed by a veterinary physician to check general health and condition of the animal before surgical procedure. The fifteen rabbits were divided into three groups, each group contained five rabbits. The groups divided according to the healing periods (1, 2, 4 weeks) and five rabbits were sacrificed for each healing period

\section{Surgical procedure}

Animals were anaesthetized with $10 \%$ ketamine (40 $\mathrm{mg} / \mathrm{kg}$ ) and $2 \%$ xylazine (5 $\mathrm{mg} / \mathrm{kg}$ ) intramuscularly. After complete anesthesia had been obtained, the animal legs hair removed and the area cleaned with hexatane solution. An incision of about $4 \mathrm{~cm}$ is made over the tibia below the knee joint using blade no. 11. After flap reflection, the periosteum is dissected bluntly and the bone is exposed. Four small cavities were made at equal distance with 2.mm in depth and diameter. The holes were drilled by low speed drill under profound saline irrigation. The holes then dried from the blood. The anterior defect were filled with OSTEON material and gelatin sponge, the second defect filled with PRP carried by gelatin sponge, the third defect filled with gelatin sponge only and the last defect filled with OSTEON and PRP carried by gelatin sponge. The wound dried and closed with black silk suture and disinfected with Hexatane and an aluminum number was placed around the healthy leg.

\section{Radiographical Observation}

All specimens were subjected to radiographical examination to assess the amount of bone formation by digital radiograph system using periapical sensor and attached to it wire length $10 \mathrm{~mm}$ for later calibration. The exposure was $63 \mathrm{Kv}$ for 
$0.080 \mathrm{sec}$. The percentage of bone formation was measured by three examiners in separated manner and as follows:

Area of bone formation $=$ Total defect area

$\neg$ - Non formed bone area

Percentage of bone Formation= area of bone formation / total defect area $\times 100$

\section{Histological Observation}

Specimens were preserved in $10 \%$ formaldehyde, and processed to prepare slides stained with hematoxylin and eosin reagent, and examined under light microscope at power (x 100).

To assess the speed of healing, the criteria were designed as follows: Presence of osteoid, this signifies a healing process in bone, Presence of granulation tissue which make up the whole of early stages of healing with inverse relationship in the final stages by accumulation of osteoid and inflammatory cells which scattered between granulation tissue. These findings were scored semi quantitatively depending on the microscope finding of the three variables as (-) for absence, $(+)$ for mild presence, $(++)$ for moderate presence and $(+++)$ for abundance.

\section{Statistical Analysis:}

The data were processed statistically using the SPSS version 18.0 for Windows 7. The association between variables for radiographical and histological analysis was studied using: " ANOVA one way analysis of variance to comparing difference between group of same period and comparing each group at different time interval.

» Post Hoc test to determine the group that led to the difference within the same period of time and determine the time that led to differences for histological finding

» Duncan Multiple Analysis Rang Test to determine the group that led to the difference within the same period of time and determine the time that led to differences for radiographical findings.

\section{RESULTS}

\section{Radiographical results}

On first week postoperatively, all four defects were simply detected. After first week, no significant difference was found between the four groups. However, control group showed more radiolucent pattern. The OSTEON material particles can be detected at the bottom of the $1^{\text {st }}$ and $4^{\text {th }}$ defects. After two weeks, the material still appeared at the $1^{\text {st }}$ and $4^{\text {th }}$ defects. The OSTEON /PRP showed nearly a complete filling of the defect with new. The OSTE$\mathrm{ON}$ and the control showed no differences in the amount of bone formation. At the fourth week postoperatively, the PRP group showed the most bone formation value followed by OSTEON / PRP, control and OSTEON as shown in (Figure1)



A- one week postoperative radiograph: All four defects were simply detected after first week. Control group show more radiolucent pattern. The material can be detected at the bottom of the 1st and 4th defects 


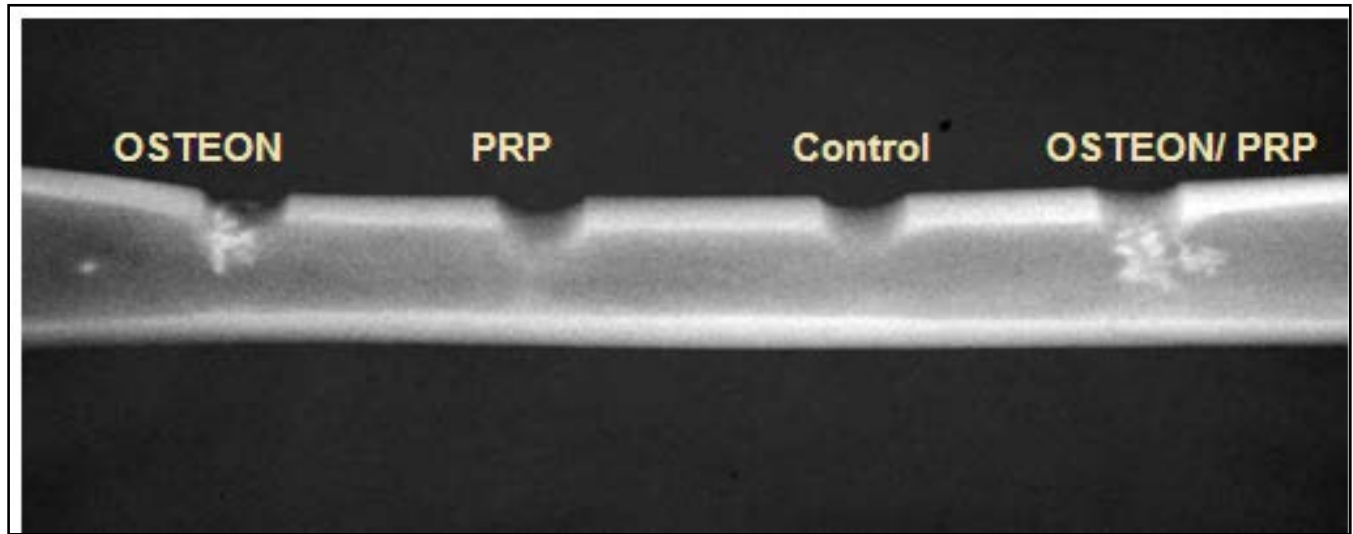

B-Two weeks post operative radiograph: The material still appear at the 1st and 4th defects. The OSTEON /PRP showed nearly complete fill with new bone followed by PRP, OSTEON group and finally the control group.

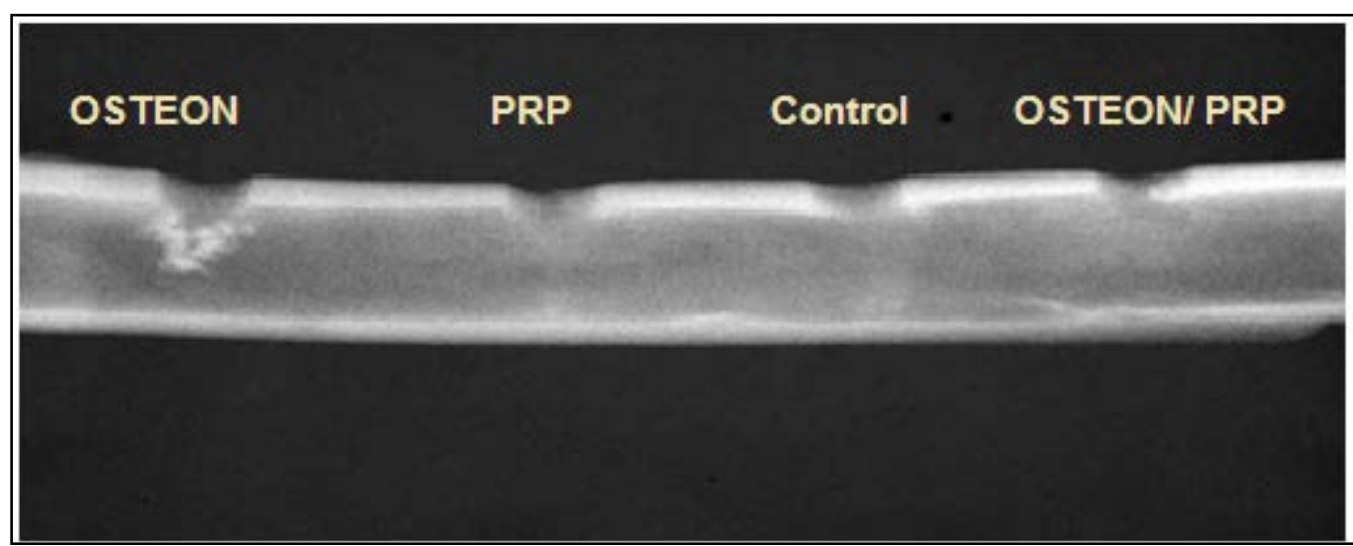

C- Four weeks postoperative radiograph: The OSTEON group showed slightly more radiolucency that other groups and the OSTEON material appears at the bottom of the first defect. The other three groups are nearly completely filled with new bone

Figure (1): Postoperative Radiograph: A after one week, B after two weeks, C after four weeks

\section{Histopathological Results}

At the first week, all groups except the OSTEON / PRP showed inflammatory reactions and abundant amount of inflammation was seen in group OSTEON alone. Granulation tissues appeared in all groups.

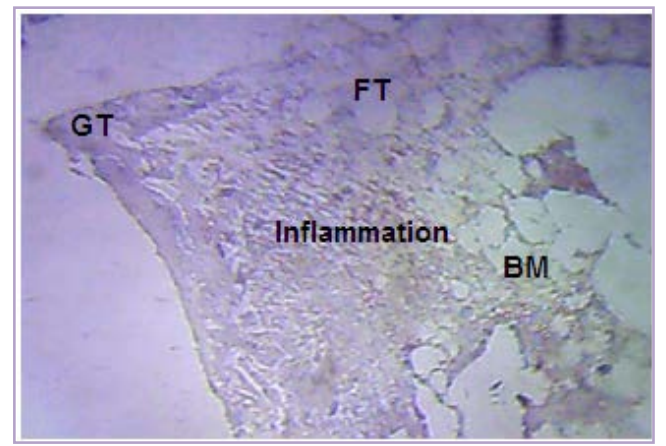

PRP group showed mature granulation tissue with new blood vessels and fibroblast. Inflammation was found in fewer amounts than in the OSTEON. New bone formation not found
The PRP group showed the greatest amount of granulation tissue and the OSTEON was the least. Only the OSTEON / PRP group showed new bone formation as shown in Figure (2).

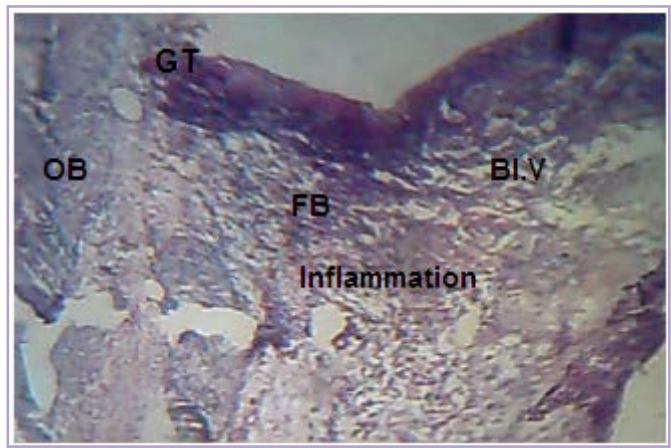

OSTEON group showed abundance of inflammation. Granulation tissue present in moderate amount at the border with newly formed blood vessels. No new bone was found 




The control defect consist of mature granulation tissue and inflammatory cells infiltrates

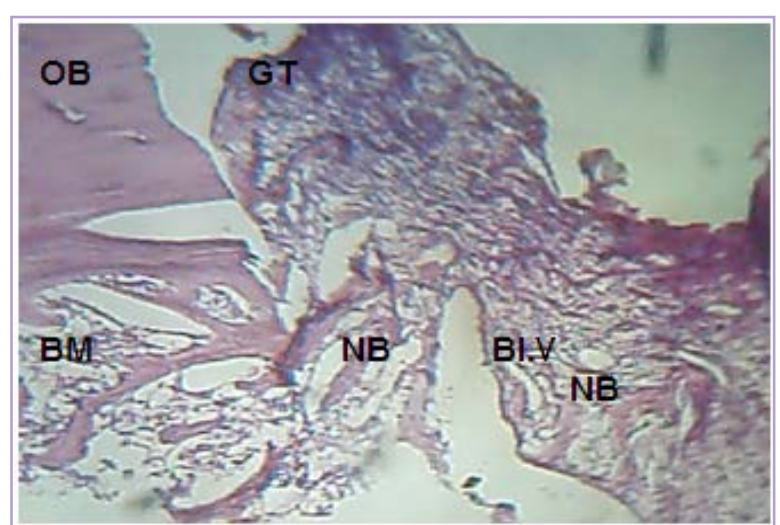

The OSTEON / PRP group showed new bone found at the defect border attached to the original bone and scattered throughout the defect. Areas of granulation tissue also present

Figure (2): Photomicrographs of one week Period groups (magnification power x 100): A OSTEON, B PRP, C Control, D OSTEON/ PRP (GT: granulation tissue, FT: fatty tissue, BM: bone marrow, OB: old bone, BL.V: blood vessels NB: new bone)

At the end of second week, the new bone scattered throughout vascularized granulation tissue in all groups. Control group showed minimal amount of new bone which is thinner than other groups. Chronic inflammatory infiltrate and granu-

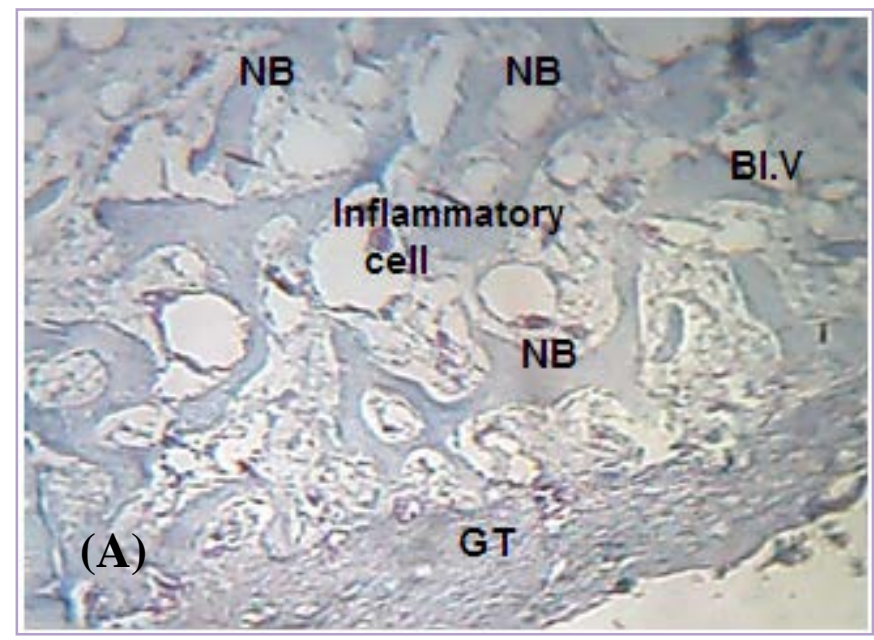

OSTEON showed the new bone scattered throughout the lesion with newly formed blood vessels, inflammatory cells and granulation tissue present in this group lation tissue found in greater amount in control group than other groups. The OSTEON/ PRP group showed nearly complete bridging of the defect with mature new osteod tissue as shown in Figure (3).

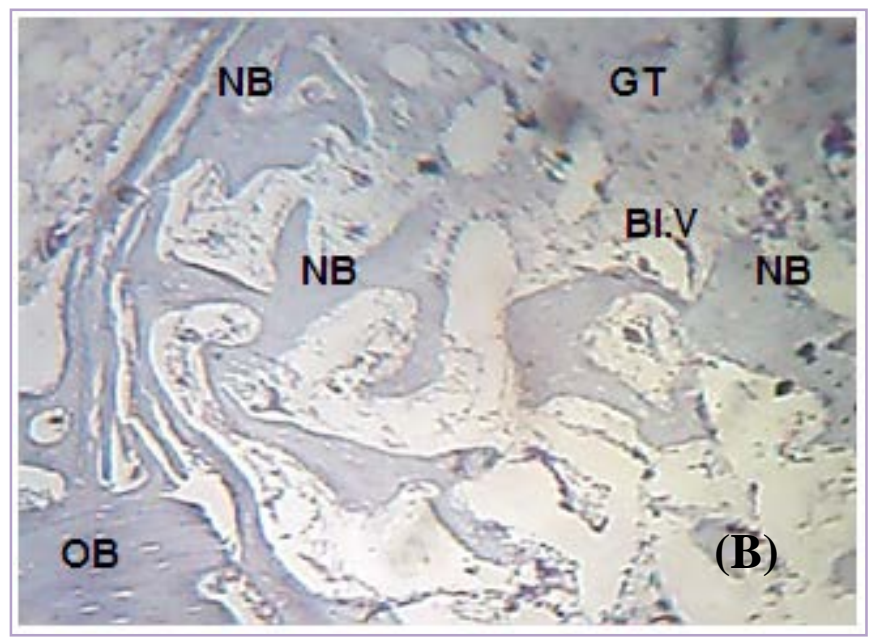

PRP group showed new bone formation on vascularised granulation tissue ground and few inflammatory cells 


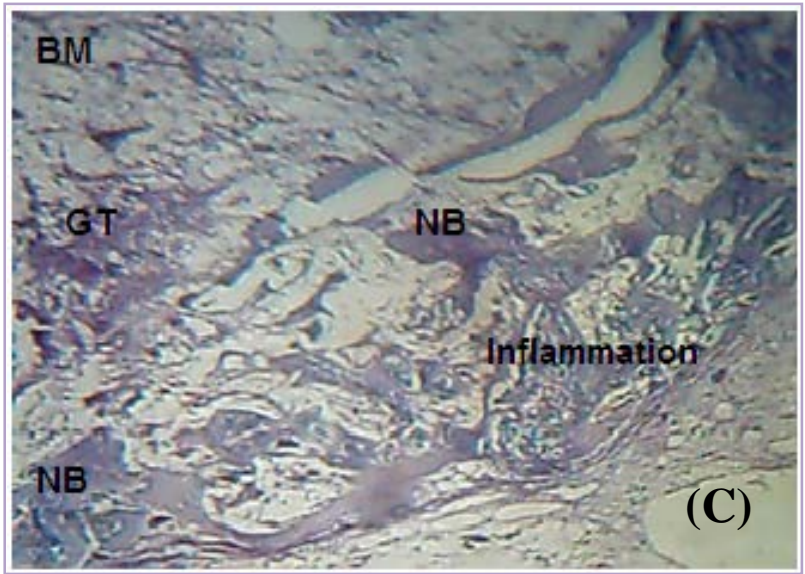

Control group showed minimal amount of new bone which is thinner than other groups. Chronic inflammatory infiltrate and granulation tissue found in greater amount than other groups



The Osteon/ PRP group showed nearly complete bridging of the defect with mature new osteod tissue and little fibrous tissue in between the new bone

Figure (3): Photomicrographs of two weeks Period groups (magnification power x 100): AOSTEON, B PRP, C Control, D OSTEON/ PRP.

At the end of fourth week, new osteod tissue was shown to fill the entire defect with little granulation tissue foci scattered throughout the new bone in all groups. OSTEON/ PRP group showed the highest amount of new bone formation. No inflammation was found in all groups as shown in Figure (4).

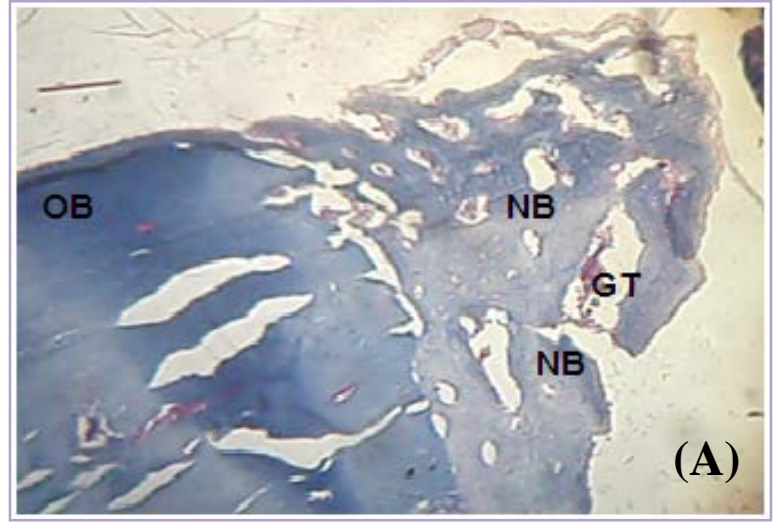

OSTEON group showed the new bone formed filled theentire defect with little granulation tissue fociscattered throughout the new bone

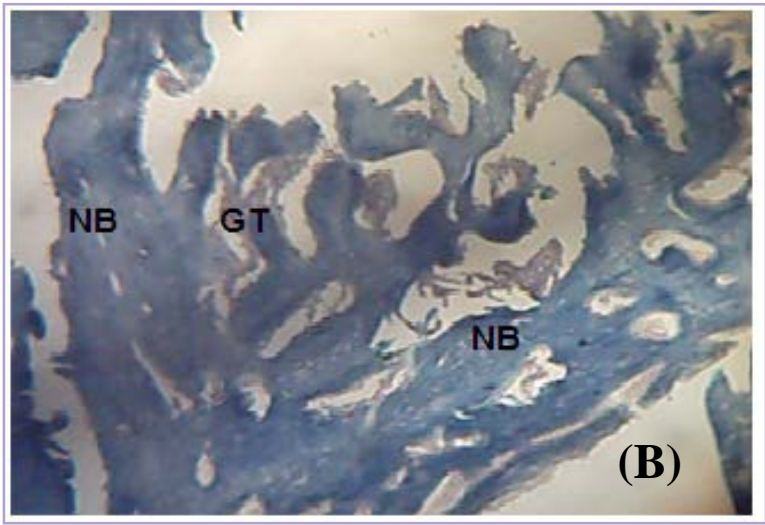

PRP group showed few amount of granulation tissue and heavy amount of new bone. The new bone also fills the entire defect as in Osteon group 


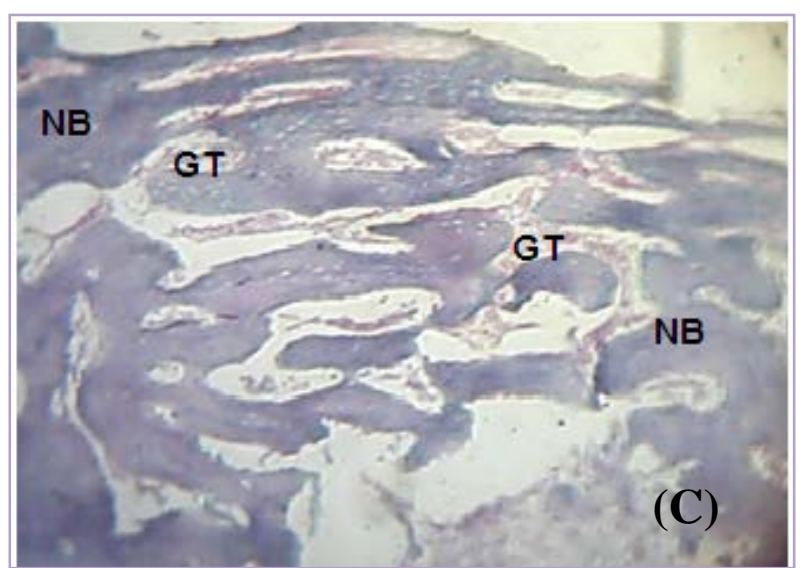

Control section showed little granulation tissues seen throughout the newly formed bone which fills the defec.

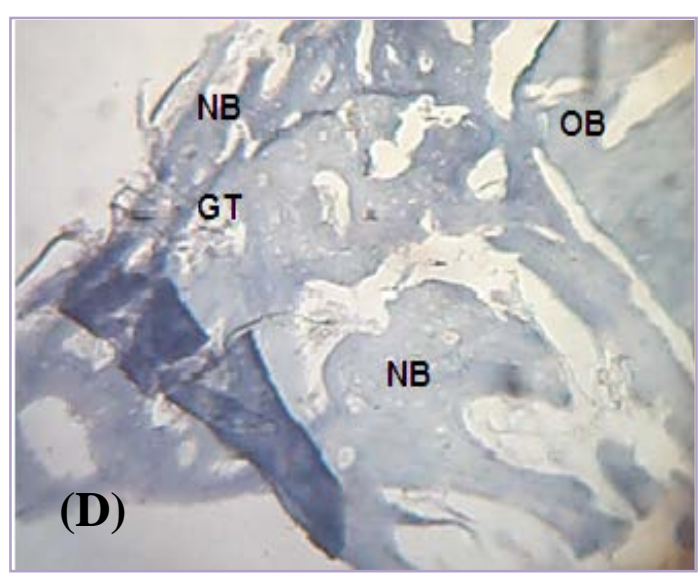

OSTEON / PRP group showed the highest amount of new bone formation and the least amount of granulation tissue

Figure (4): Photomicrograph of fou weeks period (magnification power x 100): A OSTEON, B PRP, Control, D OSTEON/ PRP. Statistical evaluation

Statistical evaluation

Regarding to radiographical evaluation, ANOVA table for 1 week revealed that $P$ value was $0.237>0.05$ which indicates that there was no significant difference between groups. At the second week, $\mathrm{P}$ value was $0.000<0.05$ which indicated that OSTEON / PRP group and PRP alone group showed significant difference from control and OSTEON groups. At the fourth week, $\mathrm{P}$ value was $0.001<0.05$ which indicated significant difference of PRP group with OSTEON and control, but it was not significant difference with OSTEON / PRP group. On the other hand, OSTEON / PRP group was significantly different from OSTEON alone but showed no significant difference with control. OSTEON and control showed no difference Table (1).

Table (1): Mean and $P$ values for Radiographical Findings using ANOVA and Duncan Multiple Analysis rang Test

\begin{tabular}{cccc}
\hline $\begin{array}{c}\text { Period of heal- } \\
\text { ingTreatments }\end{array}$ & $\begin{array}{c}\text { One } \\
\text { Week }\end{array}$ & Two weeks & Four Weeks \\
\hline OSTEON & $\mathrm{A}$ & $\mathrm{A}$ & $\mathrm{A}$ \\
& 70.7600 & 70.4240 & 68.6800 \\
PRP & $\mathrm{A}$ & $\mathrm{B}$ & $\mathrm{C}$ \\
& 73.6640 & 81.5580 & 83.2640 \\
Control & $\mathrm{A}$ & $\mathrm{A}$ & $\mathrm{AB}$ \\
& 66.9300 & 68.2080 & 75.3120 \\
OSTEON/ PRP & $\mathrm{A}$ & $\mathrm{B}$ & $\mathrm{BC}$ \\
\hline P value & 79.1880 & 82.9760 & 81.7920 \\
\hline * mean significant at $\mathrm{p} \leq 0.05$ & 0.237 & $0.000^{*}$ & $0.001^{*}$ \\
Capital letters mean comparison between materials & &
\end{tabular}


Regarding of histopathological results, ANOVA table for the first week revealed that $P$ value for inflammation variable was $0.000<0.05$ which indicates that Inflammation in OSTEON and Control groups was significantly different from OSTEON / PRP and PRP groups. P value for granulation tissue variable was $0.029<0.05$ that the PRP group was significantly different from OSTEON and control. New bone formation showed $\mathrm{P}$ value $0.000<0.05$ which indicated that OSTEON / PRP group was significantly different from other group. At the second week, ANOVA table revealed that $\mathrm{P}$ value was 0.272 ,
$0.774,0.588>0.05$ for the inflammation, granulation tissue and osteod tissue variables respectively. This indicates there were no significant differences between the four groups at the second week for all variables.At the fourth week, ANOVA table revealed that $\mathrm{P}$ values were 0.441 and $0.446>0.05$ for the granulation tissue and osteod tissue variables respectively. This indicates no significant difference between all groups regarding to the mentioned variables. All specimens of the four groups were out of inflammation in the 4th week so a $\mathrm{P}$ value was not found Table (2).

Table (2): Mean and P-values of Histological Findings for inflammation, Granulation tissue and Osteod using ANOVA and Post Hoc test

\begin{tabular}{|c|c|c|c|c|c|}
\hline \multirow[b]{2}{*}{ Treatment } & \multicolumn{5}{|c|}{ Inflammation } \\
\hline & OSTEON & PRP & Control & OSTEON/ PRP & $\begin{array}{c}\mathbf{P} \\
\text { Value }\end{array}$ \\
\hline \multirow{4}{*}{ One Week } & $\mathrm{b}$ & $\mathrm{a}$ & C & $\mathrm{a}$ & \multirow{3}{*}{$0.000 *$} \\
\hline & 0.61 & 0.2 & 0.5 & 0 & \\
\hline & $\mathrm{B}$ & A & $\mathrm{B}$ & A & \\
\hline & $\mathrm{a}$ & $\mathrm{a}$ & $\mathrm{b}$ & $\mathrm{a}$ & \multirow{3}{*}{0.272} \\
\hline \multirow[t]{2}{*}{ Two Weeks } & 0.09 & 0.072 & 0.17 & 0.04 & \\
\hline & $\mathrm{A}$ & A & $\mathrm{A}$ & $\mathrm{A}$ & \\
\hline \multirow{2}{*}{ Four Weeks } & $\mathrm{a}$ & a & $\mathrm{a}$ & a & \multirow{3}{*}{ - - } \\
\hline & 0 & 0 & 0 & 0 & \\
\hline$P$ value & $0.000^{*}$ & 0.096 & $0.000^{*}$ & 0.397 & \\
\hline Variable & \multicolumn{5}{|c|}{ Granulation tissue } \\
\hline Treatment & OSTEON & PRP & Control & OSTEON/ PRP & $\begin{array}{c}\mathbf{P} \\
\text { Value }\end{array}$ \\
\hline \multirow{4}{*}{ One Week } & $\mathrm{a}$ & C & $\mathrm{b}$ & $\mathrm{b}$ & \multirow{4}{*}{$0.029 *$} \\
\hline & 0.39 & 0.8 & 0.5 & 0.65 & \\
\hline & A & A & A & $\mathrm{AB}$ & \\
\hline & $\mathrm{a}$ & $\mathrm{b}$ & $\mathrm{b}$ & $\mathrm{b}$ & \\
\hline \multirow[t]{3}{*}{ Two Weeks } & 0.56 & 0.472 & 0.51 & 0.468 & \multirow[t]{2}{*}{0.774} \\
\hline & A & A & A & A & \\
\hline & $\mathrm{a}$ & $\mathrm{a}$ & a & $\mathrm{a}$ & \multirow{3}{*}{0.441} \\
\hline \multirow[t]{2}{*}{ Four Weeks } & 0.2 & 0.1 & 0.2 & 0.05 & \\
\hline & A & $\mathrm{A}$ & A & A & \\
\hline$P$ value & 0.058 & $0.000 *$ & 0.03 & $0.000 *$ & \\
\hline
\end{tabular}




\begin{tabular}{cccccc}
\hline variable & \multicolumn{5}{c}{ Osteod Tissue } \\
Treatment & OSTEON & PRP & Control & OSTEON/ PRP & $\begin{array}{c}\text { P } \\
\text { value }\end{array}$ \\
\hline \multirow{2}{*}{ One Week } & $\mathrm{a}$ & $\mathrm{a}$ & $\mathrm{a}$ & $\mathrm{a}$ & \\
& 0 & 0 & 0 & 0.35 & $0.000^{*}$ \\
& $\mathrm{~A}$ & $\mathrm{~A}$ & $\mathrm{~A}$ & $\mathrm{~B}$ & \\
Two Weeks & $\mathrm{b}$ & $\mathrm{b}$ & $\mathrm{b}$ & $\mathrm{a}$ & 0.588 \\
& 0.32 & 0.428 & 0.38 & 0.49 & \\
& $\mathrm{~A}$ & $\mathrm{~A}$ & $\mathrm{~A}$ & $\mathrm{~A}$ & \\
Four Weeks• & $\mathrm{C}$ & $\mathrm{C}$ & $\mathrm{C}$ & $\mathrm{b}$ & \multirow{2}{*}{ ( } \\
& 0.81 & 0.9 & 0.8 & 0.95 & 0.446 \\
P value & $\mathrm{A}$ & $\mathrm{A}$ & $\mathrm{A}$ & $\mathrm{A}$ & \\
\hline
\end{tabular}

Mean significant at $p \leq 0.05$

- All specimens of all treatment were out of inflammation in the $4^{\text {th }}$ week so $p$ values was not found Capital letters mean comparison between treatments (Horizontally), small letters mean comparisons between periods of healing (Vertically

\section{DISCUSSION}

This study showed enhancement of bone formation by using combination of PRP with an osteoconductive bone substitute. PRP's growth factors have the potential to affect growth and differentiation of cells involved in bone regeneration. At the same time, the wound site will benefit from the osteoconductive and space available by OSTEON material. PRP contains high concentration of fibrin, this will produce a sticky property that works as stabilizing factor for blood clot and bone graft that prevent their immobilization at wound site. ${ }^{(11)}$ Bone substitutes may play a role in keeping the level of growth factor that is required for the events leading to bone formation. ${ }^{(12)}$ Ilgenli, 2007 proposed that when two distinct wound healing principles applied together in one clinical situation. This will enhance and fastening healing process ${ }^{(13)}$.Many studies found that there was better results by adding PRP to different bone subsitutes material. ${ }^{(13-17)}$ This study also showed better results when using a combination method. Other studies found no benefits were gained from a combination treatment.$^{(18-22)}$

Although OSTEON / PRP showed increase amount of bone formation, it was not significantly different with PRP alone except on the first week. PRP provides a high level of growth factors exceeds those released by the body and so accelerate healing. The efficacy of PRP lies in their ability to locally deliver a wide range of growth factors and proteins which supporting reparative tissue processes. ${ }^{(23,24)}$ The majority of the presynthesized bioactive proteins are released within one hour of clot formation. The additional amount released by PRP could increase the rate of precursor cells migration and proliferation within hours and days. The activated platelets will be able to produce and secrete these protein factors for 5-10 days. ${ }^{(25)}$ PRP considered as an easy and relatively cheap way to obtain these various cytokine and growth factors as they can prepared intra-operatively. ${ }^{(26)}$ This study showed that application of PRP to the bone defects will enhance the new bone formation; the same finding by Marx (2004), Pessoa et al. (2009), Berghoff et al. (2006), Graziani et al. (2006), Verrier et al, (2010). ${ }^{(24-}$ 28) Other studies done by Casati 2007 and Sarkar 2006 who stated that there was no benefit obtained by adding PRP to the defect site. $(29,30)$

Tricalcium phosphate (TCP), hydroxyapatite (HA) and other bone substitutes have been used as scaffolds for the repair of bone defects. Most of these biomaterials were found to be too rigid or fragile. On the other hand, bioabsorbable materials are designed to degrade and disappear over a short period of time, so it will have a low mechanical strength .$^{(14)}$ This can be applied to our material which consists of HA \& TCP. Our study found that using OSTEON alone is not an effective therapy for treatment of bone defects. Kim et al. (2008) showed that no significant difference 
was observed when using OSTEON graft material, which is the same finding in this study. As a result, the study showed that treatment of bone defect with OSTEON alone is not considered as an effective treatment. Adding of PRP to the material will enhance the healing and gives better results due the additive effect of the action of concentrated growth factors.

On the other hand, two millimeters bone defect of the rabbit's leg is not a critical-sized defect $^{(19)}$, as at second and fourth weeks most of the defects were already closed with new bone. Further research with defect sized more than 2 millimeters is required to confirm this result.

\section{CONCLUSION}

Combination of PRP with osteoconductive bone substitute material OSTERON can accelerate bone defect healing by enhance early new bone formation..

\section{REFERENCES}

1. McAllister BS, Haghighat K. Bone Augmentation Techniques. J Periodontol 2007; 78 (3): 377-379.

2. Tutt B. Recent advances in technology have enabled surgeons to perform facial reconstruction with a degree of precision that was impossible just a few years ago. Oncolg; 2011; 56 (2):1-3.

3. Molla MR, Azim KA, Nabi AEU, Chowdhury MS. General Principles of Bone Grafting in Maxillofacial Surgery. The ORION; 2001; 8: 1-4.

4. Mah J, Hung J, Wang J, Salih. The efficacy of various alloplastic bone graft on the healing of rat clavarial defect. Eur.Jou.Orth; 2004; 26 ( 5) : 475-482

5. Habibovica P, Gbureckc U,. Doillond CJ,. Bassetta DC, Blitterswijkb CA,Barrale JE.Osteoconduction and osteoinduction of low-temperature3D printed bioceramic implants. Biomaterials ; 2008; 29: 944-953.

6. Kim YK, Yun PY, Lim SC, Kim SG, Lee HJ, Ong JL.Clinical evaluations of Osteon as a new alloplastic material in sinus bone grafting and its effect on bone healing.J Biomed. Mat. Res. B Appl Biomater; 2008; 86:270-7.

7. FourumS J, Stephen SW, Dennis PT, Sang-Choon Ch. Effect of Platelet-Rich Plasma on Bone Growth and Osseointegration in Human Maxillary Sinus Grafts. The International Journal of Periodontics \& Restorative Dentistry; 2002; 22 (1): 4546.
8. Jameson CA. Autologous Platelet Concentrate for the Production of Platelet Gel. LABMEDICIN; 2007; 38 (1): 39-42.

9. Carlson N and Roach RJR. Platelet-rich plasma Clinical applications in dentistry. J Am Dent Assoc; 2002; 133(10): 1383-1386

10. Fox JG, Cohen BJ, Loew FM. Laboretory Animal MedicineInBivin WS, Smith GD (Eds.) Techniques of experimentations. Academic Press, Flourida, USA.1984; Ch 19: 565- 567.

11. Camargo PM, Lecovic N, Weinlaender M, Vasilik N, Madzarevic M, Kenney EB. A Reentry Study on the use of Bovine Porous Bone mineral, GTR, and platelets rich plasma in the regenerative treatment of intrabony defects in human. International journal of periodontics and restorative dentistry; 2005; 25 (1): 49-59.

12. Tsay RC, Jennifer VO, Burke A, Sidney BE, $\mathrm{Lu} \mathrm{HH}$, and Landesberg R . Differential Growth Factor Retention by Platelet-Rich Plasma Composites. J oral maxillofacial Surg; 2005; 63: 521-528.

13. Ilgenli T, Dündar N, Kal BI. Demineralized freeze-dried bone allograft and plateletrichplasma vs platelet-rich plasma alone in infrabony defects:a clinical and radiographic evaluation. Clin Oral Invest; 2007; 11:51-59.

14. ZHAnG Y, WAnG G, Sun Y, ZHAnG C. Combination of platelet-rich plasma with degradable bioactive borate glass for segmental bone defect repair. Acta Ortho. Bel; 2011; 77: 110-115.

15. Dallari D, Fini M, Stagni C, Torricelli P,Aldini NN, Giavaresi G, Cenni E, Baldini N,Cenacchi A, Bassi A, Giardino R, Fornasari PM,Giunti A. In Vivo Study on the Healing of Bone Defects Treated with Bone Marrow Stromal Cells, Platelet-Rich Plasma, and Freeze-Dried Bone Allografts, Alone and in Combination. Journal of Orthopedic Research; 2006 : 877888.

16. Ivan C. Oppourtunities The Useof PlateletRich Plasma Presents For Increasing Osteogenesis InOral Surgery. Journal of IMAB - Annual Proceeding (Scientific Papers); 2005; 2: 26-28.

17. Shayesteh YS, Khorsand A, Motahhary P, Dehghan M, Ardestani MS. Evaluation of Platelet-Rich Plasma in Combination with Deproteinized Bovine Bone Mineral in the Rabbit Cranium; A Pilot Study. J Dent. 2005; 2 (4) : 127- 134.

18. Dőri F. Effect of combined therapeutical methods on healing of intra-bony defects in regene 
ative periodontal surgery. Ph.D.Thesis. Sem- Materials; 2010; 20: 403 - 414.

melweis University; 2008; : 66-83.

19. Plachokova AS, Dolder J, Stoelinga PJ, Jansen JA. Early effect of platelet-rich plasma on bone healing in combination with an osteoconductive material in rat cranial defects. Clin. Oral Impl. Res; 2007;18: 244251.

20. Jensen TB, Rahbek O, Overgaard S,.Søballe K. No effect of platelet-rich plasma with frozen or processed bone allograft around noncemented implants. International Orthopaedics (SICOT); 2005; 29: 67-72.

21. SteigmannM and Garg AK. A Comparative Study of Bilateral Sinus Lifts Performed with Platelet-Rich Plasma Alone Versus Alloplastic Graft Material Reconstituted with Blood. Implant Dentistry ; 2005;14(3):261 - 265.

22. Smith RG, Gassamann CJ and Campbellp MS. Platelet-rich Plasma: Properties and Clinical Applications. The Journal of Lancaster General Hospital ; 2007; 2(2): 73-78.

23. Simman R, Hoffmann A, Bohinc RJ, Peterson WC, Russ AJ. Role of PlateletRich Plasma in Acceleration of Bone Fracture Healing. Annals of Plastic Surgery; 2008; 61( 3) : 337-344.

24. Berghoff WJ, Pietrzak WS, Rhodes RD . Platelet-Rich Plasma Application during Closure Following Total Knee Arthroplasty. Orthopedics; 2006; 29:590.

25. Verrier S, Meury TR, Kupcsik L, Heini P, StollT, and Alini M.Platelets-Released Supl ment Induces Osteoblastic Differentiation of Human Mesenchymal Stem Cell: Potential Role of BMP-2. Eureorpian cells and
26. Marx RE. Platelet Rich Plasma: Evidence to Support Its Use. J Oral Maxillofac Surg; 2004; 62:489-496.

27. Pessoa RS, Oliveira SR, Menezes HM, Magalhaes D. Effects of platelet-rich plasma on healing of alveolar socket: Split-mouth histological and histometric evaluation in Cebus apella monkeys. Indian Journal of Dental Research.; 2009; 20 (4): 442-447.

28. Graziani F, Ivanovski S, Cei S, Ducci F, Tonetti $\mathrm{M}$ and Gabriel $\mathrm{M}$. The in vitro effect of different PRP concentrations on osteoblasts and fibroblasts. Clin Oral Impl Res; 2006; 17: 212-219.

29. Casati MZ, Vasconcelos Gurgel BC, Goncalves PF, Pimentel SP, Rocha Nogueira Filho G, Nociti J FH, Sallum EA. Platelet-rich plasma does not improve bone regeneration around peri-implant bone defects-A pilot study in dogs. Int. J. Oral Maxillofac. Surg ; 2007; 36: 132-136.

30. Sarkar MR, Augat P, Shefelbine SJ, Schorlemmer S, Huber-Lang M , Claes L, Kinzl L, Ignatius $\mathrm{A}$. Bone formation in a long bone defect model using a platelet-rich plasmaloaded collagen scaffold. Biomaterials ; 2006; 27: 1817-1823.

31. Gogolewski S, Nonmetallic material for bone substitute. European Cells and Materials; 2001; 1(2): 54-55.

32. Al- Attar B.H. Bone regeneration Using Hydroxyapitite Granules with and without Guided Bone regenerative Membrane. M.Sc. Thesis. University of Mosul; 2011 